\title{
Small bowel transit of a bran meal residue in humans: sieving of solids from liquids and response to feeding
}

\author{
J M Hebden, P E Blackshaw, A C Perkins, M D'Amato, R C Spiller
}

\begin{abstract}
Background-Ileal motor patterns are adapted to the propulsion of viscous meal residue, such as bran, which accumulates in the distal ileum postprandially.

Aims-To examine the effects of a second liquid/solid meal on ileal emptying.

Subjects and methods-Eleven healthy fasting subjects consumed a $1.47 \mathrm{MJ}$ pancake containing $15 \mathrm{~g}$ bran and $5 \mathrm{MBq}$ Technetium-99m labelled amberlite resin (meal A). Gastric emptying and transit through the left upper quadrant (proximal) and right lower quadrant (distal) small bowel regions and colon were assessed scintigraphically. Transit was compared with and without a second Indium111 liquid/solid DTPA labelled 2.28 MJ meal (B) given three hours after the first meal.
\end{abstract}

Results-Gastric emptying of meal A was slower than meal B (the time for $50 \%$ of the activity to leave the stomach $\left(T_{50}\right)$ being 113 (11) minutes versus 48 (3) minutes respectively, $p<0.01, n=11)$. Both meals passed rapidly through the proximal small bowel ( $T_{50}$ meal $A=57$ (14) minutes versus $T_{50}$ meal $B=42$ (11) minutes). Transit of meal A through the distal small bowel was much slower $\left(T_{50}\right.$ more than 390 minutes versus 176 (29) minutes for meal $B, p<0.01$ ), resulting in meal $B$ overtaking meal $A$ and entering the colon earlier. Ingestion of the second meal $(B)$ resulted in significantly less meal A marker entering the colon (5 (3)\%) at 11 hours than when meal A was taken alone (18 (4)\%) $(\mathrm{p}<0.05, \mathrm{n}=8)$.

Conclusions-The distal small bowel selectively retains bran, allowing liquid phase markers through to the colon. Consuming a second liquid/solid meal does not stimulate ileal transit of bran which seems to be propelled quicker by fasting motor patterns.

(Gut 1998;42:685-689)

Keywords: ileum; motility; bran; feeding

Pharmacology, Rotta

Research

Laboratorium, Monza,

Italy

M D'Amato

Correspondence to:

Dr R C Spiller,

Division of Gastroenterology,

University Hospital,

Nottingham NG7 2UH, UK.

Accepted for publication 26 November 1997

Absorption of fluids and nutrients in the upper small intestine is usually rapid, ${ }^{12}$ such that the terminal ileum receives relatively small volumes of fluid containing indigestible, often viscous meal residues. The flow of this residue increases two to four hours postprandially, ${ }^{3}$ and the pharmacology and specific motor patterns and reflexes of the ileum ${ }^{4-6}$ discussed below, can be seen as an adaptation to its unique environment, lying between the jejunum and colon.

During fasting, aboral flow through the terminal ileum is greatest immediately before the passage of a phase III of the migrating motor complex, ${ }^{3}$ but also occurs with discrete clustered contractions and infrequent prolonged propulsive pressure waves which migrate distally in both man and dogs. ${ }^{5-7}$ Unlike those seen in dogs, ${ }^{78}$ human phase IIIs do not regularly pass through the terminal ileum ${ }^{59}$ and emptying of the terminal ileum is more erratic, occurring for the most part without obvious relation to readily recognisable motor patterns. ${ }^{10}$

The discrete clustered contractions and the isolated prolonged propagated pressure waves, in dogs at least, are powerful, propulsive motor patterns which may be regarded as an adaptation to allow propulsion of the highly viscous material which may accumulate in the distal ileum.

Bran contains a substantial amount of indigestible, viscous material which will accumulate in the distal ileum. When compacted and dehydrated, it is one of the most viscous materials which the ileum is required to transfer, and we considered this to be a good test of ileal propulsive ability. Furthermore in subjects with functional bowel disorders, bran is poorly tolerated ${ }^{11}$ and associated with increased sensation of bloating. ${ }^{12}$ Previously it has been suggested that patients with irritable bowel syndrome in whom bloating is the main complaint show a defect in ileocolonic transfer of bran. ${ }^{13}$

The aim of the present study was therefore to explore further the handling of bran by the normal ileum prior to studying this phenomenon in the irritable bowel syndrome. In addition, we were particularly interested to determine whether the transit of bran through this region would be stimulated as previously described ${ }^{13}$ by feeding a second meal, either via a reflex, the "gastroileal response", or as a direct effect of the increased flow through the terminal ileum which follows two to four hours postprandially. $^{3}$

\section{Materials and methods}

SUBJECTS

Twelve healthy volunteers (four females, eight males; aged 19-47 years) were recruited into a two part study, each part separated by at least two weeks. All were free from any organic or functional gastrointestinal disorder, and taking no medication known to alter gastrointestinal 
motility. Women were required to have a negative pregnancy test within the 24 hour period prior to each of the study days. Written informed consent was obtained from all subjects and the study was approved by the University of Nottingham Medical School Ethics Committee and the Department of Health (ARSAC) and carried out according to the guidelines in the Declaration of Helsinki.

\section{STUDY DESIGN}

Two studies were performed, separated by two to four weeks, the sequence being randomised. In part 1 of the study, volunteers ingested a solid meal following an overnight fast. The meal consisted of $5 \mathrm{MBq}$ of Technetium-99m labelled amberlite resin baked into a bran supplemented pancake (1.67 MJ: Sainsbury's Batter Mix, J Sainsbury plc, London (55\% carbohydrate, $35 \%$ fat, $10 \%$ protein); $15 \mathrm{~g}$ bran, Natural wheat bran, Holland \& Barrett, Hinckley, Leicestershire, UK). Thereafter subjects remained fasted but were allowed fluids, including decaffeinated tea and coffee, until the end of the study. In part 2 of the study, an additional Indium-111 DTPA labelled liquid/ solid meal (Clinifeed 400 drink, Clintec Nutrition Ltd, Slough, UK (66\% carbohydrate, 16\% fat, $18 \%$ protein; $1.67 \mathrm{MJ}$ ) plus two digestive biscuits $(0.61 \mathrm{MJ}), \mathrm{McVitie}$ 's Digestive, $\mathrm{McVi}$ tie, Staines, Middlesex, UK) was consumed three hours after the pancake meal, following which subjects again remained fasted but were allowed fluids freely. The two meals were of very different viscosities, the liquid meal being watery (viscosity 1 Pascal sec) while the pancake was solid and required chewing prior to swallowing.

SCINTIGRAPHIC IMAGING

Anterior and posterior reference markers, consisting of ${ }^{99 \mathrm{~m}} \mathrm{Tc}$ labelled filter paper contained within a sheath of waterproof tape, were taped on to the abdomen over the right lobe of the liver anteriorly and posteriorly, and were used as guides to align successive scintigraphic images during analysis.

Anterior and posterior gamma scintigraphic images of 60 seconds duration were recorded using an IGE Maxicamera II (IGE Ltd, Herts, UK) fitted with a medium energy parallel hole collimator (300 keV maximum energy). Views were acquired using dual $20 \%$ symmetrical energy windows centred on the $245 \mathrm{keV}$ of ${ }^{111} \mathrm{In}$ and the $140 \mathrm{keV}$ photopeak of ${ }^{99 \mathrm{~m}} \mathrm{Tc}$. The images were stored on a $128 \times 128$ matrix using a dedicated Nuclear Diagnostics computer system (Gravesend, Kent, UK).

Imaging commenced immediately after ingestion of the radiolabelled pancake, and thereafter at approximately 30 minute intervals until the end of the study 11 hours later.

\section{SCINTIGRAPHIC ANALYSIS}

Scintigraphic images for each subject were reviewed, and outlines of the stomach and colon constructed. The activity in these regions was determined using a variable region of interest program. Scintigraphic counts were corrected for background radiation, radioactive decay, and for anteroposterior movement by using the geometric mean of the anterior and posterior counts. Since the higher energy ${ }^{111}$ In causes detectable counts in the lower energy ${ }^{99 \mathrm{~m}} \mathrm{Tc}$ window a correction factor was determined by assessing the apparent increase in Technetium counts immediately after the ${ }^{111}$ In was ingested. Technetium counts after the ${ }^{111} \mathrm{In}$ ingestion were then corrected for this "down scatter".

Gastric emptying time $\left(\mathrm{GE} \mathrm{T}_{50}\right)$ was taken as the time for $50 \%$ of the activity to leave the stomach, and small bowel transit (SBT) was calculated by subtracting GE $\mathrm{T}_{50}$ from the time for $50 \%$ of the activity to enter the colon. Additionally an assessment of regional SBT was made by drawing a line at 45 degrees through the small bowel region of interest, with its starting point at the hepatic flexure of the colon thereby dividing it into left upper quadrant (LUQ) and right lower quadrant (RLQ) regions. Transit through the LUQ was calculated from the difference between the time for $50 \%$ of the activity to accumulate in the RLQ or beyond and the GE $T_{50}$, whereas transit through the RLQ was calculated by subtracting the time for $50 \%$ of the counts to reach the RLQ and beyond from the time for $50 \%$ of the activity to enter the colon.

\section{STATISTICAL ANALYSIS}

Results are expressed as mean (SEM). The significance of differences between paired data was assessed using the non-parametric Wilcoxon signed rank sum test.

\section{Results}

Eleven volunteers completed the study, with one subject dropping out after the fasted study as she was unable to tolerate the bran supplemented pancake. Accurate interpretation of the scintigraphic images of the small and large bowel was possible in all subjects except for one in part 1 of the study, and two in part 2 of the study. This was due to overlap of the small bowel and colon and these studies were omitted from the analysis.

\section{GASTRIC EMPTYING}

As expected there was no difference in gastric emptying of the solid pancake meal $\mathrm{A}$ in part 1 or part 2 of the study (115 (13) versus 113 (11) minutes, $\mathrm{p}=0.38, \mathrm{n}=11)$. Gastric emptying of the pancake meal A was however significantly slower than the subsequently ingested liquid/ solid meal B in part 2 of the study with a $T_{50}$ of 113 (11) versus 48 (3) minutes respectively $(\mathrm{p}=0.004)$ (fig 1$)$, even though the energy content was slightly less $(1.67 \mathrm{MJ}$ versus $2.28 \mathrm{MJ})$.

COLONIC ARRIVAL

In part 1 of the study, 18 (4)\% of the pancake meal A label had reached the colon by the end of the study period (11 hours). Significantly less pancake meal A residue reached the colon by 11 hours in part 2 of the study (5 (3)\%, $\mathrm{p}<0.05$ ) (fig 2).

\section{SMALL BOWEL TRANSIT}

Exact calculation of the complete small bowel transit was not possible for solid pancake meal 


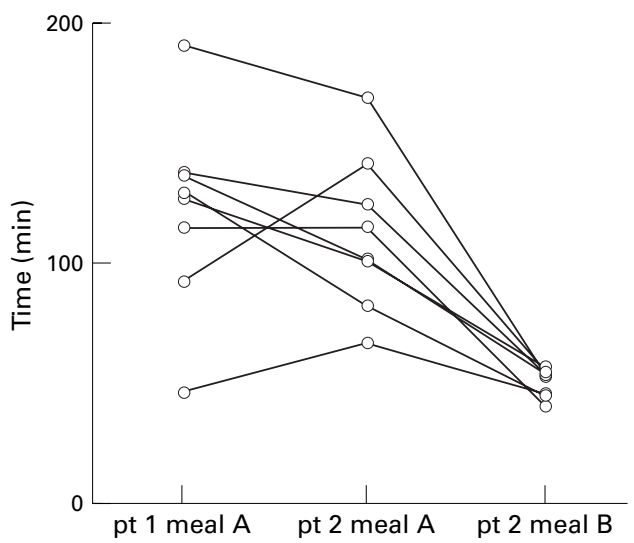

Figure 1 Scatter graph showing gastric emptying $T_{50}$ of the two meals in parts 1 and 2 of the study. The liquid meal marker (pt 2 meal B) emptied faster than the pancake meal marker in both parts of the study (pt 1 meal $A=48$ (3) minutes versus pt 2 meal $A=113$ (11) minutes, $p<0.01, n=11$ ).

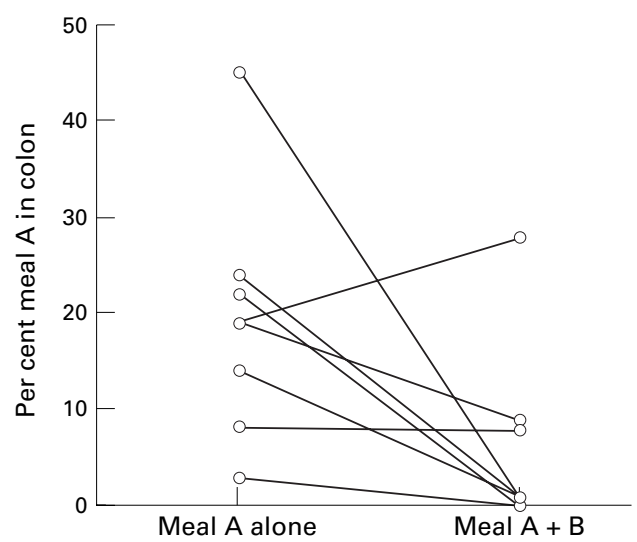

Figure 2 Percentage of the pancake meal A marker within the colon at the end of studies 1 and 2. Significantly more residue reached the colon in part 1 of the study compared with part 2 of the study (18 (4)\% versus 5 (3) \%, $p<0.05$, $n=8)$.

A, as in no study did $50 \%$ of the activity reach the colon, and indeed for most subjects less than $10 \%$ of the residue had entered the colon by 11 hours. In notable contrast, $50 \%$ or more of the liquid/solid meal $\mathrm{B}$ reached the colon in eight of the nine individuals in which analysis was possible, even though it was ingested three hours after the pancake meal $\mathrm{A}\left(\mathrm{T}_{50}\right.$ liquid/solid meal $\mathrm{B}=218$ (23) minutes versus $\mathrm{T}_{50}$ solid meal $\mathrm{A}=$ more than 488 minutes, $\mathrm{p}<0.01)$.

REGIONAL SMALL BOWEL TRANSIT

Division of the small bowel into left upper quadrant (LUQ) and right lower quadrant (RLQ) regions revealed that transit of both the solid meal $\mathrm{A}$ and liquid/solid meal $\mathrm{B}$ residue was similar and relatively rapid (57 (14) versus 42 (11) minutes respectively, $\mathrm{p}=0.16, \mathrm{n}=9$ ) through the LUQ which emptied as the RLQ filled. By contrast, transit through the RLQ was slower and showed a pronounced hold up of the solid meal residue compared with the liquid meal residue (more than 390 versus 176 (29) minutes, $\mathrm{p}<0.01, \mathrm{n}=9$ ) (fig 3 ). This sequential transit and striking difference in transit times strongly suggest that the LUQ region was predominantly proximal and the RLQ predominantly distal small bowel.

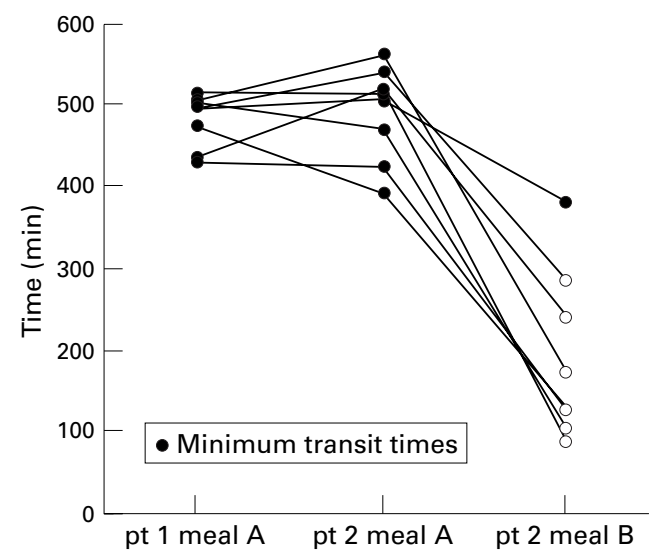

Figure 3 Scatter graph of distal small bowel transit time for the pancake meal $A$ and liquid/solid meal $B$ markers in parts 1 and 2 of the study. There was notable delay in transit of the pancake meal residue (more than 390 minutes) compared with the liquid meal residue (176 (29) minutes) through the distal small intestine in part 2 of the study $(p<0.01, n=9)$.

\section{Discussion}

The most striking observation from this study was the selective retention of pancake meal residue in the distal small bowel while the liquid label from the second meal passed through. The two meals were of very different viscosities, the more viscous pancake meal moving more slowly than the liquid meal through the stomach and distal ileum. As the egg, flour, and fat from the pancake in the first meal would have been completely digested and absorbed in the more proximal bowel, the retained residue most likely represents a viscous mass of bran. In contrast, the ${ }^{111} \mathrm{In}$ DTPA marker of the low viscosity liquid/solid meal B, taken three hours after the pancake meal, caught up with and overtook the bran residue, with the majority passing through into the colon. We consistently observed the accumulation of both the liquid phase marker, and to a much greater extent the solid phase marker, in the RLQ region of the small bowel, immediately adjacent to the lower pole of the ascending colon.

Selective emptying of liquids ahead of solids, "sieving", is well recognised in the stomach, ${ }^{14} 15$ but initial human studies comparing iodine labelled cellulose with water soluble ${ }^{99 \mathrm{~m}} \mathrm{Tc}$ DPTA suggested that this did not occur in the small bowel. ${ }^{16}$ Whether this does or does not occur may well depend on the type of solid since plainly it will require the physical separation of liquid and solid by mixing movements, which must be able to propel liquid forward while selectively retaining the larger particles as has been described with the canine stomach ${ }^{14} 15$ and rabbit colon. ${ }^{17}$ Studies in the dog have shown that the ileocolonic sphincter is able to regulate the exit of liquids from the small bowel ${ }^{18}$ which occurs in discrete boluses in both dog and man. ${ }^{7019}$ This bolus emptying would not be well suited to sieving, which seems to require passage through a longer segment of ileum, as shown by a study in which resin pellets and a liquid phase marker were infused into the ileum at either 50 or $100 \mathrm{~cm}$ proximal to the ileocaecal junction. At $50 \mathrm{~cm}$ 
both solid and liquid markers were transferred to caecum together, but when infused at 100 $\mathrm{cm}$ proximal to the ileocaecal junction, liquids were more rapidly transferred to the colon. ${ }^{20}$

Although our method of division of the small bowel into proximal and distal segments is undoubtedly only an approximation, it was nevertheless useful in that it allowed a more objective measurement of our visual impression of rapid transit through the LUQ and relative stasis in the RLQ, as previously described by others. ${ }^{2122}$ The sequential passage through the LUQ and then RLQ together with the very large differences in transit strongly suggest that the LUQ is predominantly proximal and the RUQ region predominantly distal small bowel. Overlap between the two regions does occur, but cannot be substantial because if this were so the transit times through the two regions would be much closer in value. Using this method we found transit through the proximal small bowel rapid and nondiscriminatory for solid and liquid markers. In contrast, passage of both solid and liquid meal markers through the distal small bowel was much slower, with selective retention of the solid meal residue. A similar effect can be seen even if we consider the small bowel transit as a whole, with transit time being more than 488 minutes for the most rapid transit of bran residue compared with 218 (23) minutes for the liquid meal $(\mathrm{p}<0.01)$.

There appeared to be almost complete stasis of the solid meal A residue in the distal small bowel in our study, with less than $50 \%$ entering the colon by the end of both parts 1 and 2 of the study (11 hours). We were therefore effectively studying the arrival of the "head of the meal" and in retrospect a longer study time would have been better to allow a more exact definition of the arrival time of the bulk of the meal. Thus, although the transit time through the proximal small bowel was approximately 60 minutes, distal small bowel transit time was greater than 390 minutes. The stagnation of meal A residue is probably a result of the high bran content of our pancake meal. Other studies using intubation have found transit of liquid and solid residue through the last $60-100 \mathrm{~cm}$ of ileum to be considerably faster ${ }^{10}{ }^{20}$ but this may reflect the excitatory effect of an intestinal tube. ${ }^{23}$ Exact meal composition appears to be important in determining transit in this region, as a previous study using a similar quantity of coarse bran to supplement a rice pudding meal showed a considerably faster small bowel transit time of 333 minutes. ${ }^{24}$ It is possible that in this previous study the fructose contained in the fruit jam and concentrated orange juice used with the rice pudding acted as an osmotic agent thereby accelerating transit and preventing the development of such a concentrated, viscous mass as was likely to be produced in this present study.

The other main and unexpected finding from the current study was that ingestion of the second liquid/solid meal B slowed terminal ileal emptying of the pancake meal A residue (fig 3). Although earlier reports ${ }^{25}$ suggested that a second meal would accelerate ileal tran- sit by virtue of the gastroileal response, later studies showed that although there is an initial immediate increase in motor activity this does not translate into acceleration of transit of a liquid phase marker through the distal $50 \mathrm{~cm}$ of ileum. ${ }^{7}$ Liquid transit does however accelerate two to four hours after a guar containing mixed solid/liquid meal, ${ }^{7}$ probably due to the increased flow of chyme that occurs at this time. ${ }^{3}$ Our study has shown that despite the probable increase in ileal motility induced by the second liquid/solid meal, this does not necessarily result in augmented propulsion of luminal contents, which depends on numerous other factors such as luminal viscosity and flow. We speculate that in the present study the migrating motor complex (MMC) would have reappeared four to six hours after ingesting meal A. However, ingestion of the second liquid/solid meal B would be predicted to delay further the appearance of the MMC thereby depriving the ileum of its most effective clearance mechanism for the solid meal residue. This may explain the reduced clearance of meal A ileal residue into the colon following the second liquid/solid meal, which we observed in part 2 of the study. It is possible that had our liquid meal been of a higher (4.18 MJ) energy content it would have stimulated rather than inhibited ileal emptying.

It was crucial in this study to identify and differentiate the terminal ileum and caecum accurately. This was relatively straightforward in most cases, as the Indium labelled liquid meal label passed through into the wider, readily recognisable ascending colon and so provided a clear landmark for analysis of the distribution of the Technetium label. We excluded from analysis the three studies in which this was not possible.

A further important issue relates to the solid meal A marker, Technetium, and its possible separation from the meal residue. By separately labelling the bran, we have previously shown that bran remains in close association with meal residue during gastric emptying. ${ }^{24}$ Furthermore, it is well established that amberlite resin binds Technetium avidly, and it seems likely that the resin (together with label) becomes trapped in the "mesh" of viscous bran residue after digestion of the proteinaceous elements of the pancake meal. This supposition is strengthened by the fact that the water soluble marker ${ }^{111}$ In DTPA passed through the terminal ileum, overtaking the technetium label rather than flushing it ahead.

In summary, this study has shown that the distal ileum is able to retain solid meal residue selectively while allowing liquids to pass through into the colon. Although this may allow further opportunity for digestion and absorption, it may also cause a degree of partial obstruction, perhaps accounting for the known postprandial bloating which can occur some hours following bran ingestion in the irritable bowel syndrome. ${ }^{12}$

This work was supported by a grant from Rotta Research Laboratorium and was presented at the 8th Symposium on Gastrointestinal Motility, Copenhagen, June 1996 (Neurogastroenterol 
Motil 1996;8:175), and at the British Society of Gastroenterology, Manchester, September 1996 (Gut 1996;39(suppl 1):A8).

1 Borgstrom B, Dahlqvist A, Lundh G, et al. Studies of intestinal digestion and absorption in the human. $\mathcal{F}$ Clin Invest tinal digestion an

2 Johansson C. Studies of gastrointestinal interactions VII Characteristics of the absorption pattern of sugar, fat, and protein from composite meals in man. A quantitative study.

3 Kerlin P, Zinsmeister A, Phillips S. Relationship of motility to flow of contents in the human small intestine. Gastroenterology 1982;82:701-6.

4 Kamath PS, Phillips SF, Zinsmeister AR. Short-chain fatty acids stimulate ileal motility in humans. Gastroenterology 1988;95:1496-502.

5 Quigley EMM, Borody TJ, Phillips SF, et al. Motility of the terminal ileum and ileocecal sphincter in healthy humans. Gastroenterology 1984;87:857-66.

6 Siegle ML, Ehrlein HJ. Interdigestive contractile patterns of the ileum in dogs. Am F Physiol 1987;253:G452-60.

7 Spiller RC, Brown ML, Phillips SF, et al. Scintigraphic measurements of canine ileocolonic transit: direct and measurements of canine ileocolonic transit: direct and
indirect effects of eating. Gastroenterology 1986;91:121320 .

8 Marlett JA, Code CF. Effects of celiac and superior mesenteric ganglionectomy on interdigestive myoeletric complex in dogs. Am f Physiol 1979;237:E432-6.

9 Kellow JE, Borody TJ, Phillips SF, et al. Human interdigestive motility: variations in patterns from esophagus to colon. Gastroenterology 1986;91:386-95.

10 Spiller RC, Brown ML, Phillips SF. Emptying of the terminal ileum in humans: influence of meal residue and ilea motility. Gastroenterology 1987;92:724-9.

11 Francis CY, Whorwell PJ. Bran and irritable bowel syndrome: time for reappraisal. Lancet 1994;344:39-40.

12 Snook J, Shepherd HA. Bran supplementation in the treatment of irritable bowel syndrome. Aliment Pharmacol Ther 1994;8:511-14.
13 Trottman IF, Price CC. Bloated irritable bowel syndrome defined by dynamic $99 \mathrm{mTc}$ bran scan. Lancet 1986; : 364-6.

14 Hinder RA, Kelly KA. Canine gastric emptying of solids and liquids. Am F Physiol 1977;233:335-40.

15 Meyer JH, Dressman J, Fink A, et al. Effect of size and density on canine gastric emptying of nondigestible solids. Gastroenterology 1985;89:805-13.

16 Malagelada J-R, Robertson JS, Brown ML, et al. Intestinal transit of solid and liquid components of a meal in health. Gastroenterology 1984;87:1255-63.

17 Ehrlein H-J, Reich H, Schwinger M. Colonic motility and transit of digesta during hard and soft faeces formation in rabbits. F Physiol 1983;338:75-86.

18 Kruis W, Phillips S, Zinsmeister A. Flow across the canine ileocolonic junction: role of the ileocolonic sphincter. $A m \mathcal{F}$ Physiol 1987;252:G13-18.

19 Greydanus MP, Camilleri M, Colemont LJ, et al. Ileocolonic transfer of solid chyme in small intestinal neuropathies and myopathies. Gastroenterology 1990;99:158-64.

20 Hammer J, Camilleri M, Phillips SF, et al. Does the ileocolonic junction differentiate between solids and liquids? Gut 1993;34:222-6.

21 Jian R, Pecking A, Najean Y, et al. Etude de la progression d'un repas dans l'intestin grele de l'homme par une methode scintigraphique. Gastroenterol Clin Biol 1979;3:755-62.

22 Rosa-e-Silva L, Troncon LEA, Oliveira RB, et al. Rapid distal small bowel transit associated with sympathetic denervation in type 1 diabetes mellitus. Gut 1996;39:74856.

23 Read NW, Al Janabi MN, Bates TE, et al. Effect of gastrointestinal intubation on the passage of a solid meal through the stomach and small intestine in humans. Gastroenterology 1983;84:1568-72.

24 Vincent R, Roberts A, Frier M, et al. Effect of bran particle size on gastric emptying and small bowel transit in humans: a scintigraphic study. Gut 1995;37:216-19.

25 Hertz AF. The ileo-caecal sphincter. F Physiol 1913;47:54-6. 